\title{
Hyperspectral Microwave Atmospheric Sounder (HyMAS) Architecture and Design Accommodations
}

\author{
L.M. Hilliard and P. E. Racette \\ (NASA Goddard Space Flight Center)
}

\section{W. Blackwell, C. Galbraith, E. Thompson (MIT Lincoln Laboratories)}

\section{IEEE Aerospace Conference- Big Sky, Montana March 4, 2013}

This work was sponsored by the National Aeronautics and Space Administration under the Earth Science Technology Office Advanced Component Technology (ACT) and Air Force Contract FA8721-05-C-0002. Opinions, interpretations, conclusions, and recommendations are those of the authors and are not necessarily endorsed by the United States Government. 


\section{Outline}

- Overview

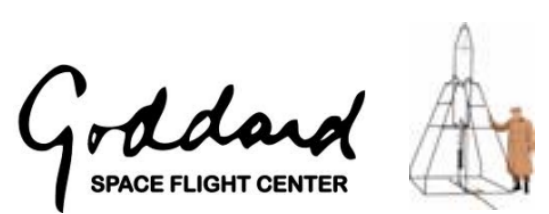

圆

- HyMAS frontend architecture/frequency plan/design

- Prototype IF processor Design and Mechanical Accommodation

- Interoperable Remote Component (IRC) and the Scanhead Computer

- Summary and Next Steps 


\section{Background}

- "Hyperspectral" measurements allow the determination of the Earth's tropospheric temperature with vertical resolution exceeding $1 \mathrm{~km}$

- 100 channels in the microwave

- Hyperspectral infrared sensors available since the 90's

- Clouds substantially degrade the information content

- A hyperspectral microwave sensor is therefore highly desirable
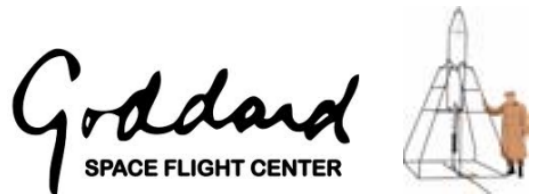

- Several recent enabling technologies make HyMW feasible:

- Detailed physical/microphysical atmospheric and sensor models

- Advanced, signal-processing based retrieval algorithms

- RF receivers are more sensitive and more compact/integrated

- The key idea: Use RF receiver arrays to build up information in the spectral domain (versus spatial domain for STAR systems) 


\section{Microwave Atmospheric Sensing}

\section{Wavelength}

(meters)
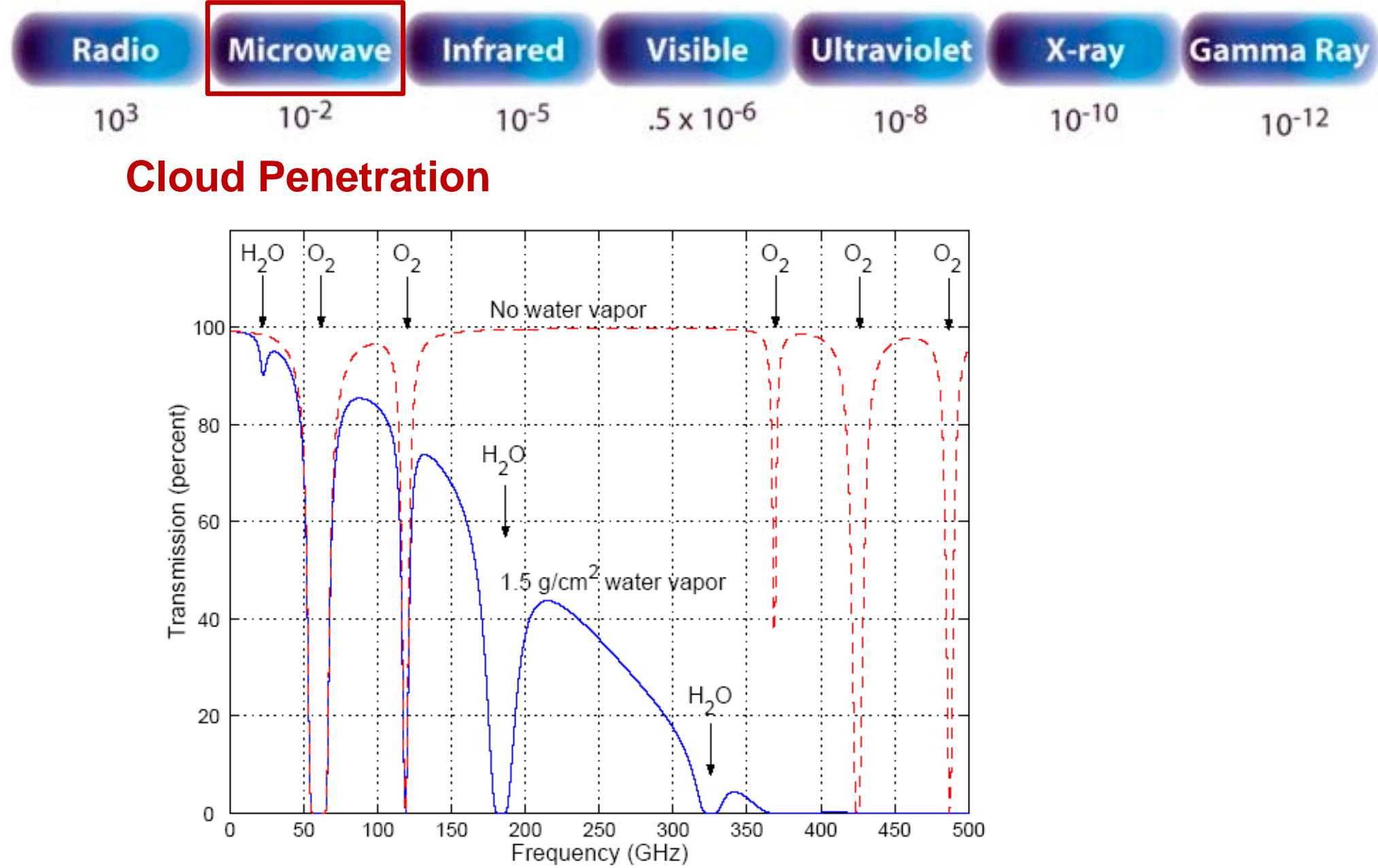

The frequency dependence of atmospheric absorption allows different altitudes to be sensed by spacing channels along absorption lines 


\section{HyMAS Overview}

- HyMAS comprises multiple receivers at $118.75 \mathrm{GHz}$ (oxygen absorption line) and 183.31 (water vapor absorption line)

- Independent RF antenna/receiver arrays sample same volume of the earth's atmosphere at slightly different frequencies

- Yields a set of dense finely spaced vertical weighting functions via frequency multiplexing

- HyMAS will be integrated into a scanhead compatible with the NASA GSFC Conical Scanning Microwave Imaging Radiometer (CoSMIR) to facilitate demonstration and performance characterization

- Limited volume of the existing CoSMIR scanhead requires an ultra compact receiver system

- Ultra compact 52-channel IF Processor (Key technology development) 


\section{Hyperspectral Microwave Operation}
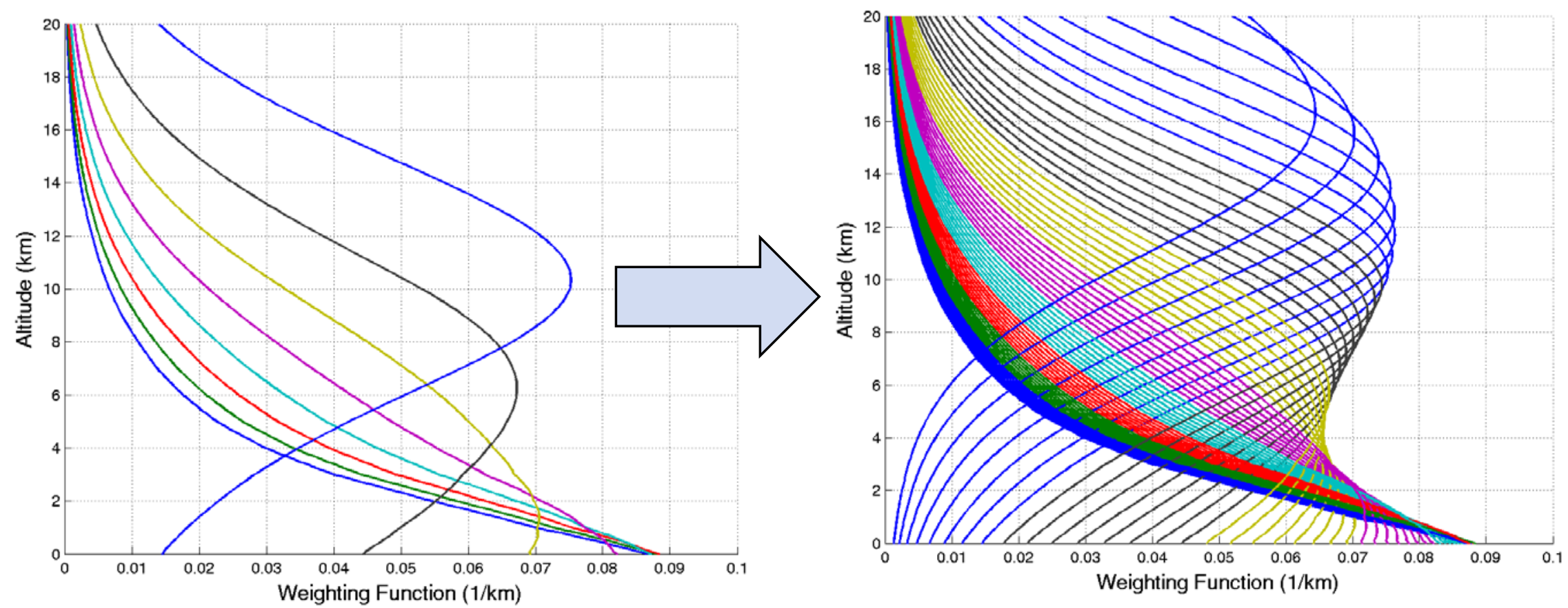

- Hyperspectral microwave operation is achieved by replicating an 8-channel receiver multiple times with slight frequency shift

- Channel center frequency is shifted by $70 \mathrm{MHz}$

- Template weighting function of single receiver replicated into an aggregate set of eight receivers 


\section{Outline}

- Overview

- HyMAS frontend architecture/frequency plan/design

- Prototype IF processor Design and Mechanical Accommodation

- Interoperable Remote Component (IRC) and the Scanhead Computer

- Summary and Next Steps 


\section{HyMAS Block Diagram}

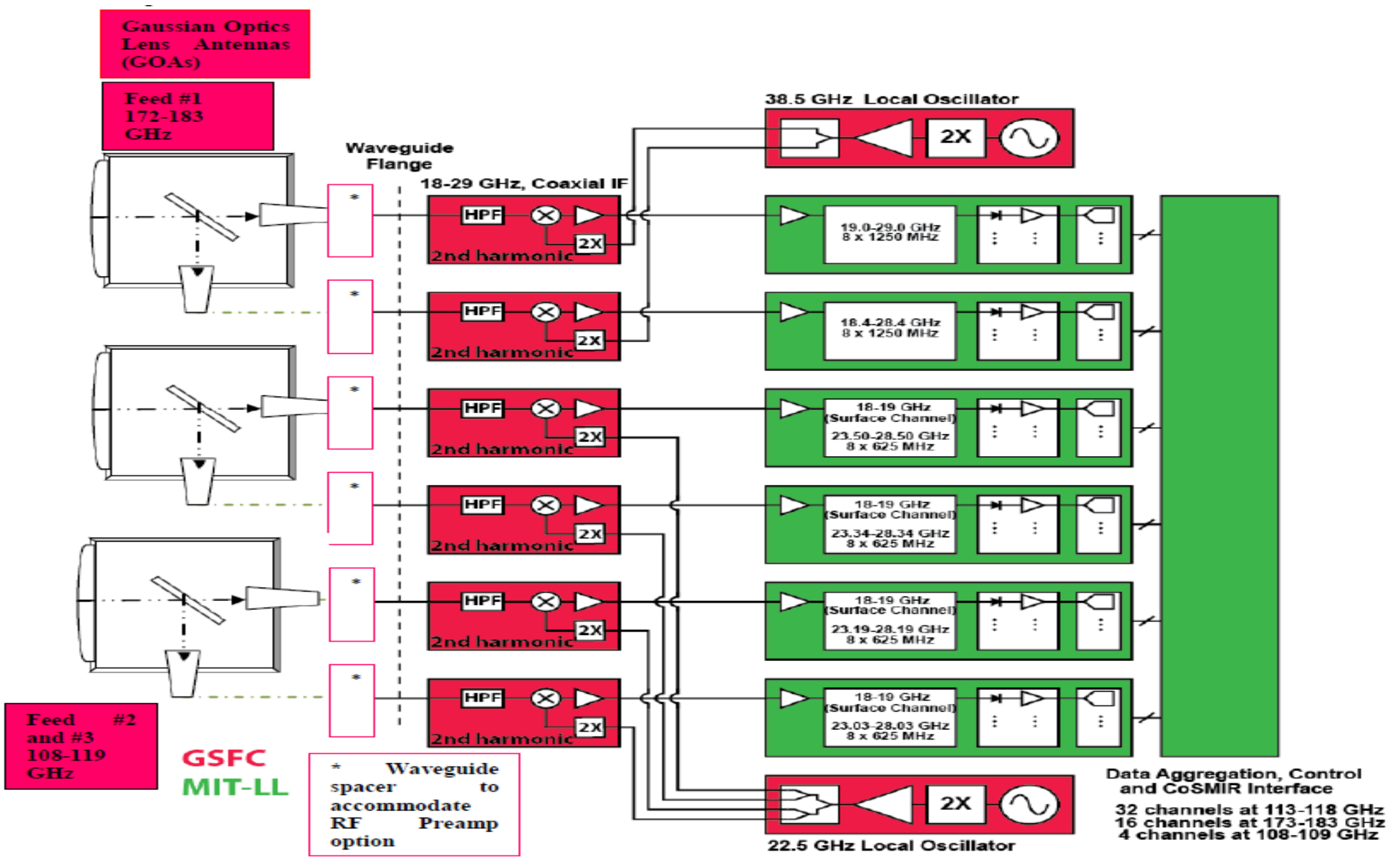

Figure 1 - Block diagram showing both the HyMAS RF electronics and core technology in the IF filter bank 


\section{HyMAS Antenna Subsystem}

Three antennas

One at $183 \mathrm{GHz}$

Bandwidth $172-183 \mathrm{GHz}$

Beamwidth: 3.1 - 3.3 degrees over the bandwidth

Sidelobes: $30 \mathrm{~dB}$ below main lobe

VSWR: $<1.5: 1$

Polarization: dual linear

Two at $118 \mathrm{GHz}$

Bandwidth $108-119 \mathrm{GHz}$

Beam width: 3.1 - 3.3 degrees over the bandwidth

Side lobes: $30 \mathrm{~dB}$ below main lobe

VSWR: $<1.5: 1$

Polarization: dual linear

Photo/Information courtesy of Millitech Inc.
Gaussian optic antenna with wire grid to separate polarizations
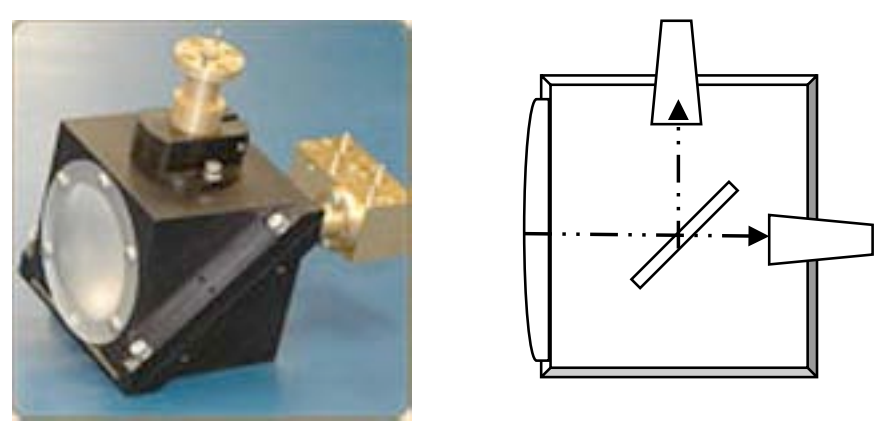

Antenna pattern analysis using $16 \mathrm{~dB}$ aperture taper achieves sidelobe requirement

Antenna Power Pattern

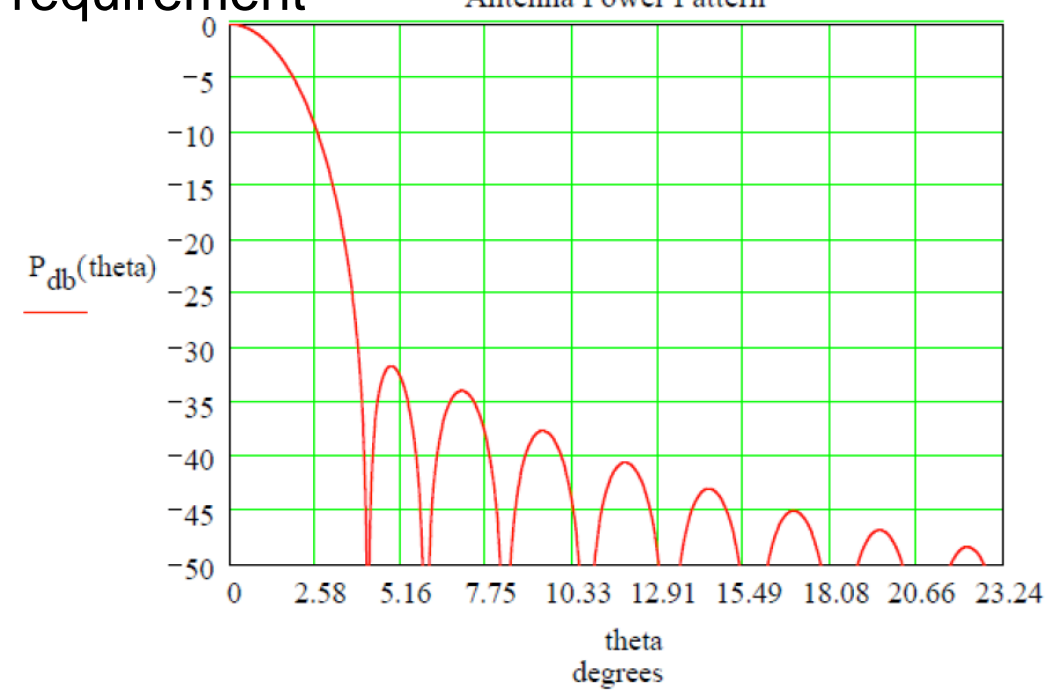




\section{HyMAS Antenna Patterns must be well matched and co-aligned}

HyMAS drum and placement

$183 \mathrm{GHz}$ GOA antenna and receiver

(1 shown but dual linear Polarization are planned)

E

2

side
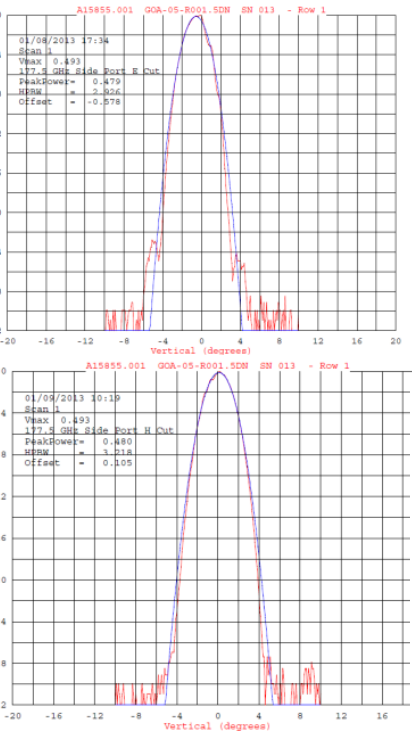

rear

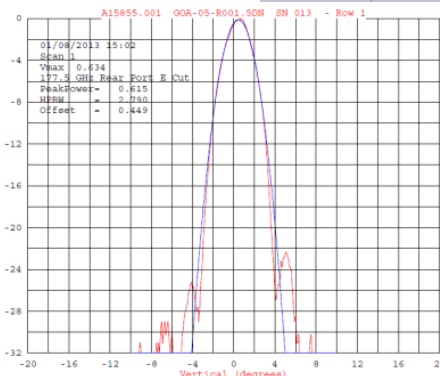

of GOAs in wall

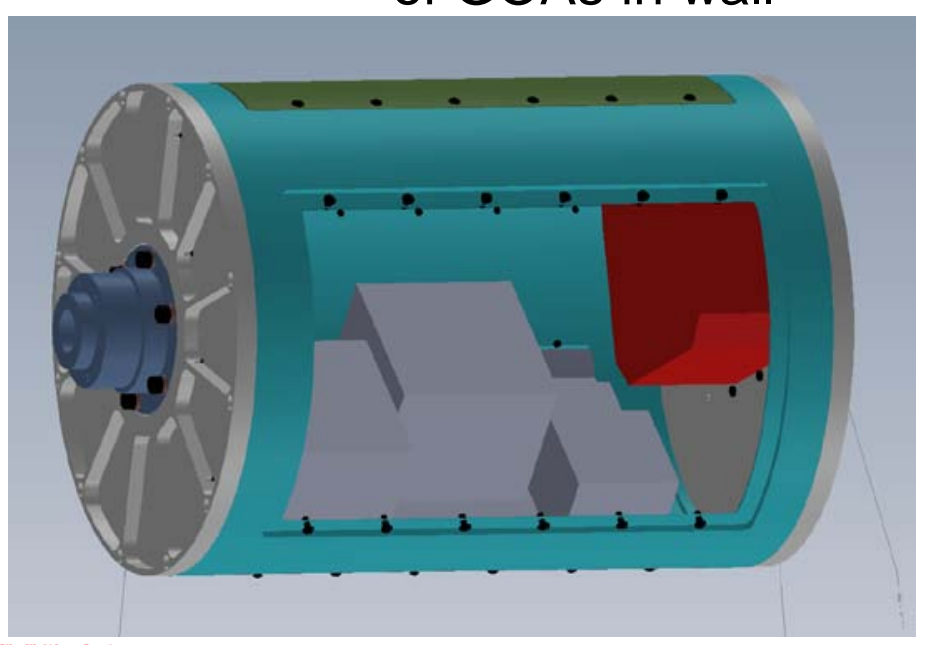

side

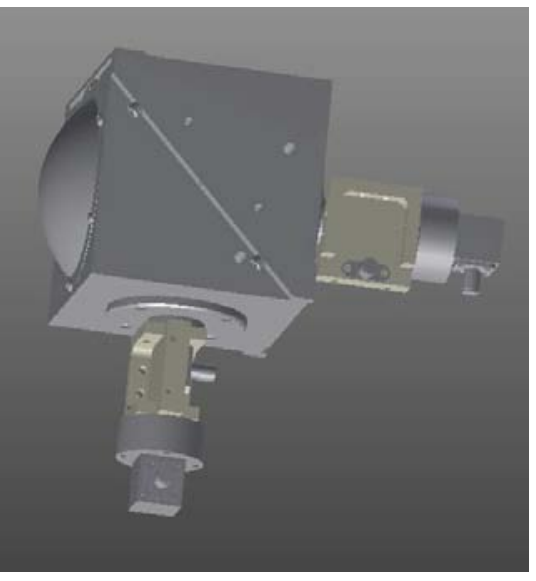

rear

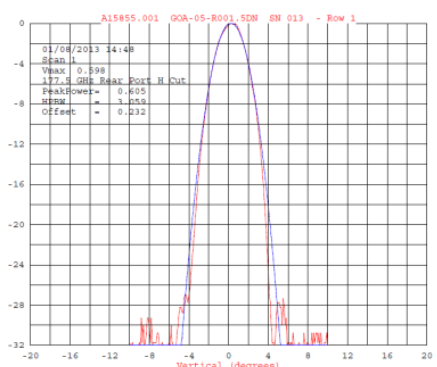

E-plane cuts

$\mathrm{H}$-plane cuts

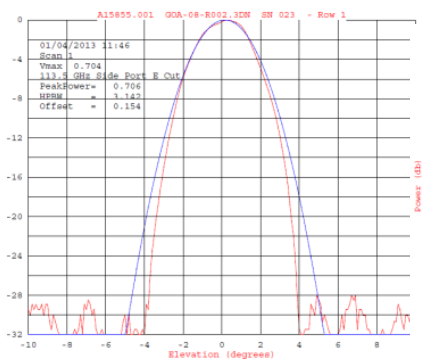

Photo/Information courtesy of Millitech Inc.
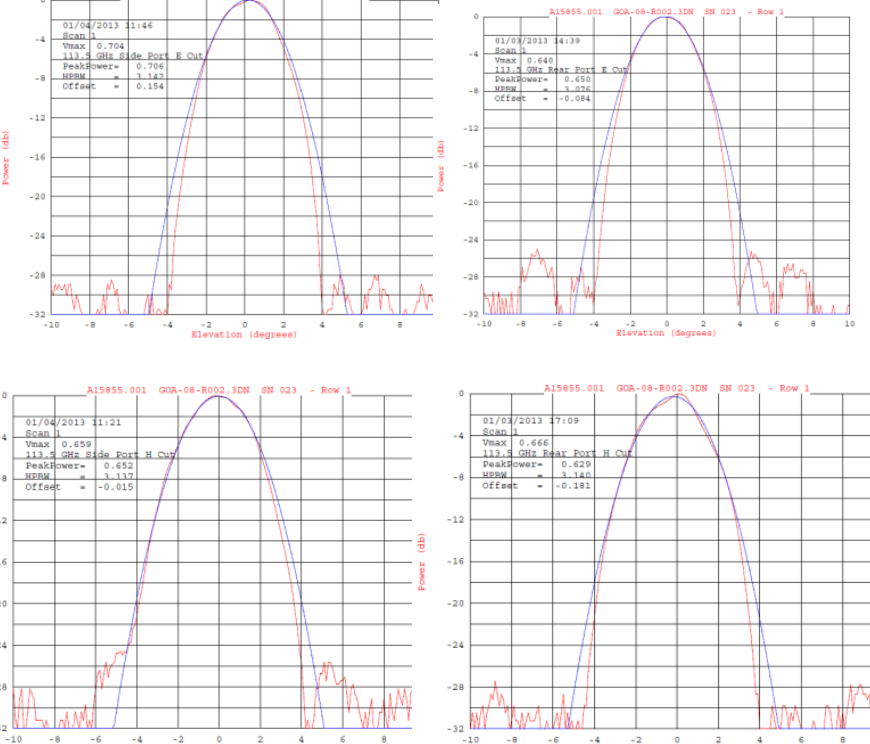


\section{HyMAS Receiver Front End}
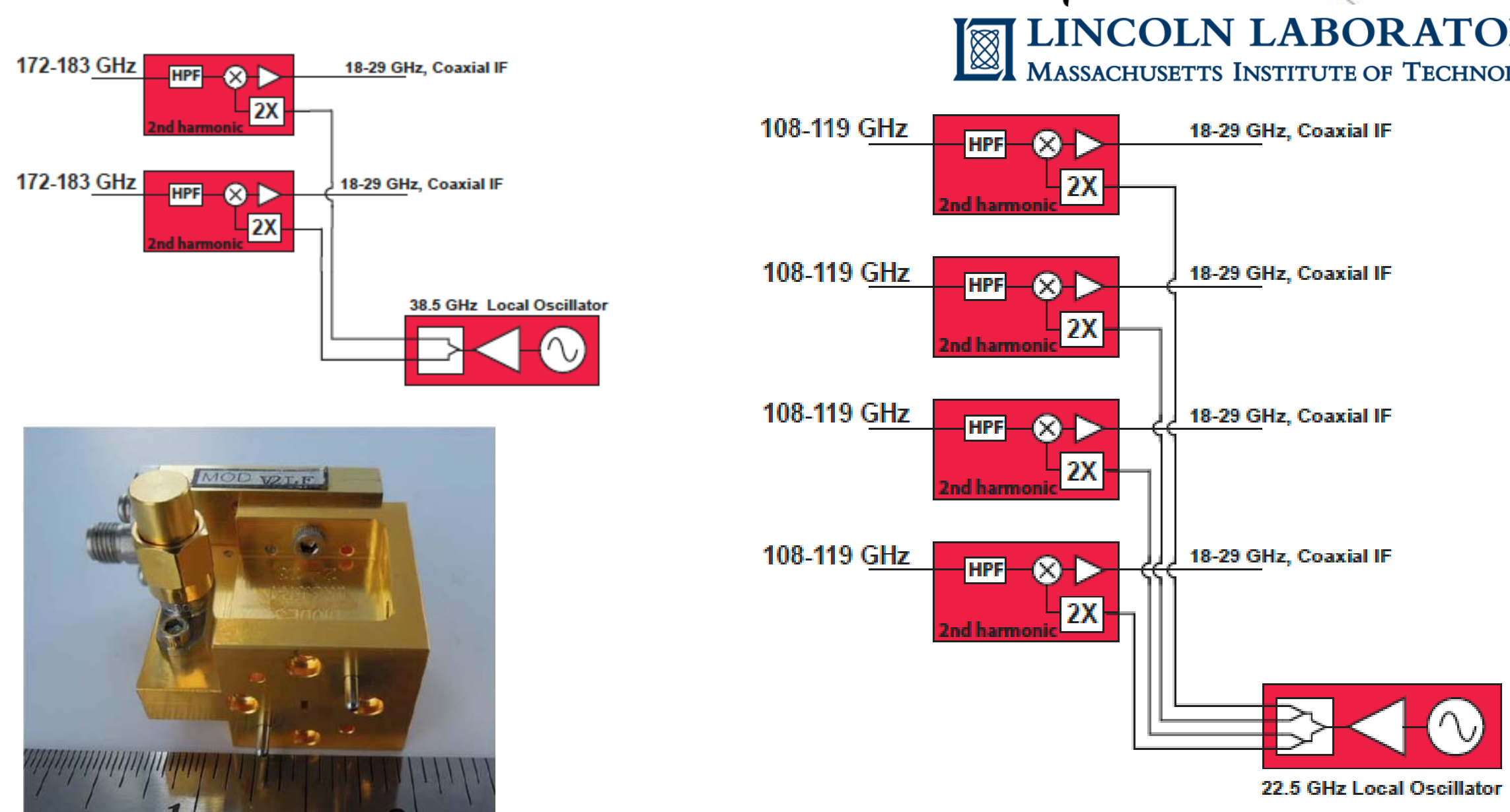

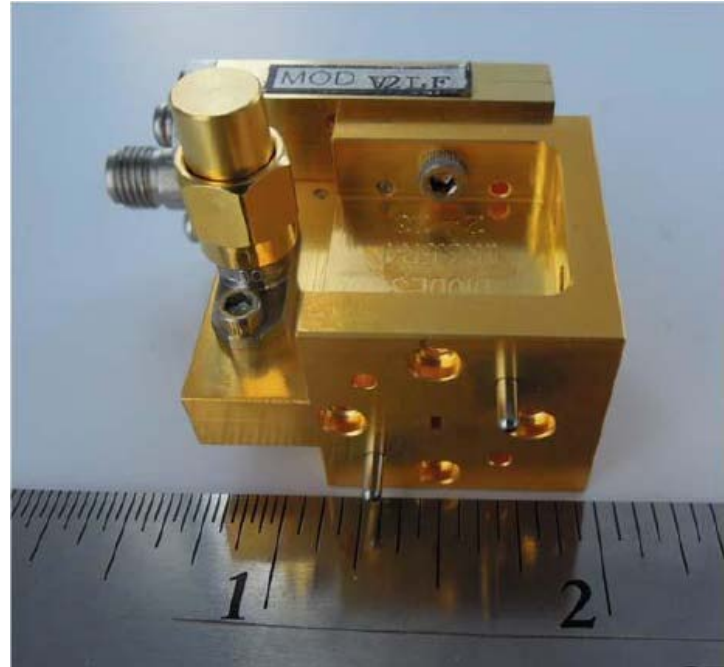

Integrated mixer amplifier (photo courtesy of Virginia Diodes Inc.)
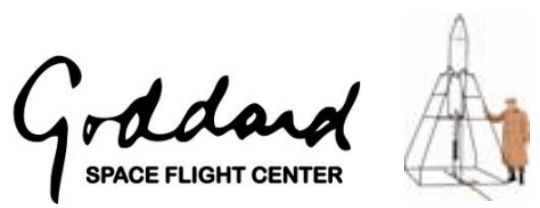


\section{Outline}

- Overview

- HyMAS frontend architecture/frequency plan/design

- Prototype IF processor Design and Mechanical Accommodation

- Interoperable Remote Component (IRC) and the Scanhead Computer

- Summary and Next Steps 


\section{IF Processor Design}

- IF processor "back-end" functions

- Amplify, channelize and detect 18-29 GHz IF band

- Post-detection filtering, A/D conversion, data processing

- COTS parts for availability, low cost

- K-connector (18-29 GHz) input from Receiver front-end

- 18-29GHz COTS amplifier

- Multiplexer channelizes IF band

- LTCC SIW filters for high performance, small size

- Detectors detect power at output of each channel

- Op-amps amplify detector output, anti-alias filtering, drive ADC

- Microcontroller sequences data flow 


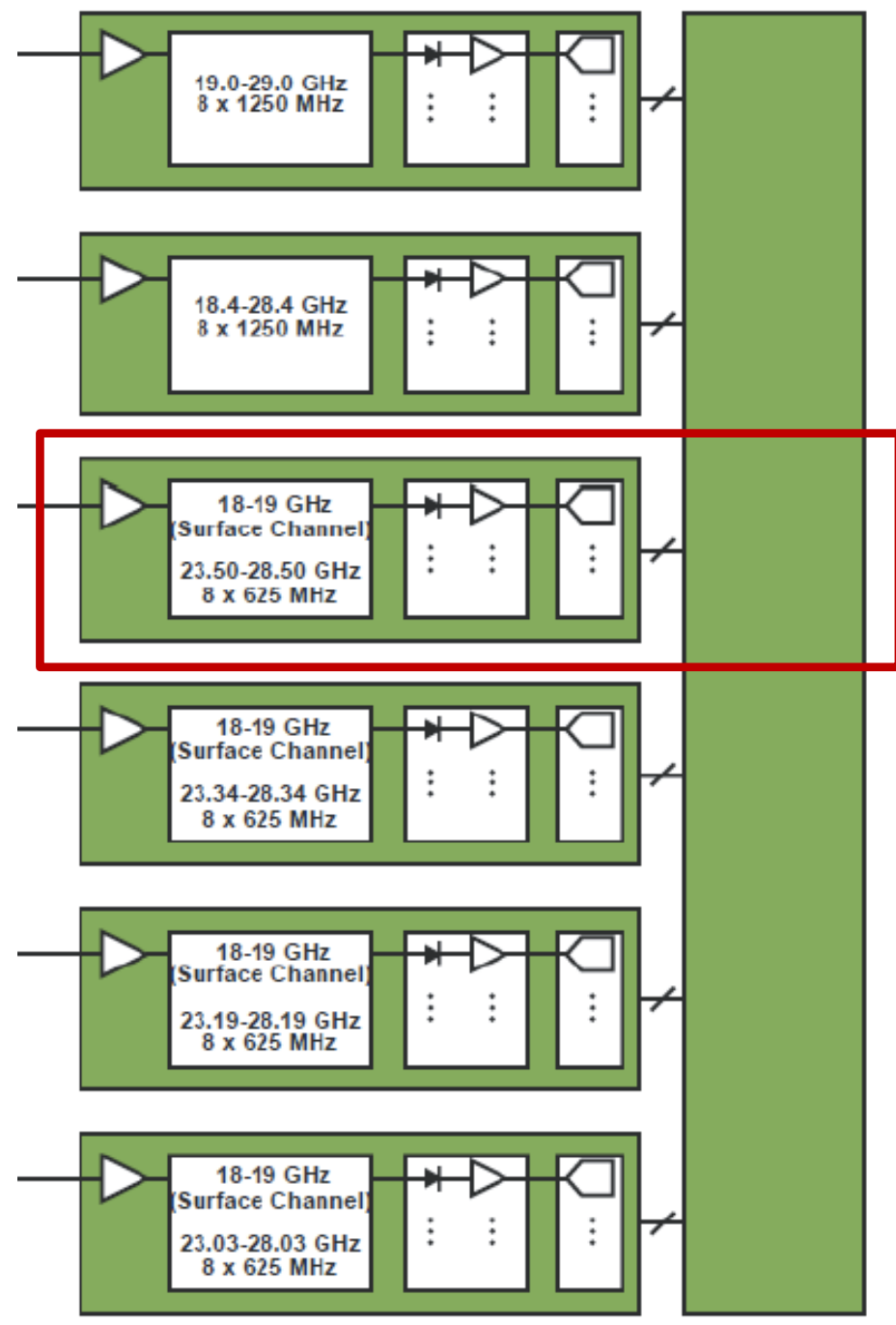

- 52 HyMAS channels designed using 6 filter banks

- Each filter bank implemented via "horizontal resonator" architecture

- Filter design implemented such that a stackable (vertical) implementation of the 6 filter banks is possible to mitigate volume constraints

- A 9-channel bank of filters selected for fabrication as a proof-of-concept 


\section{9-ch IFP Prototype Block Diagram}

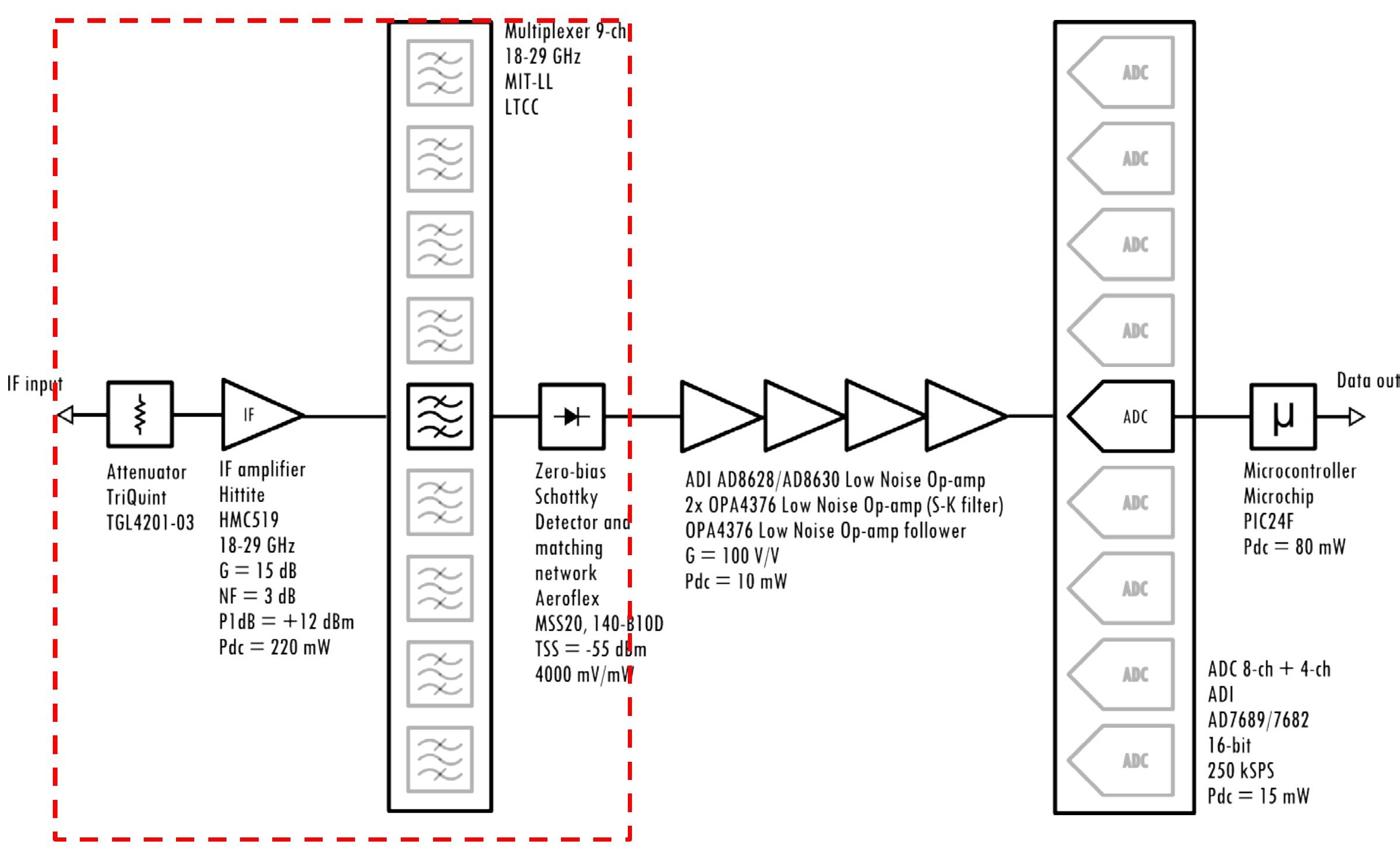




\section{RF Board Layout}

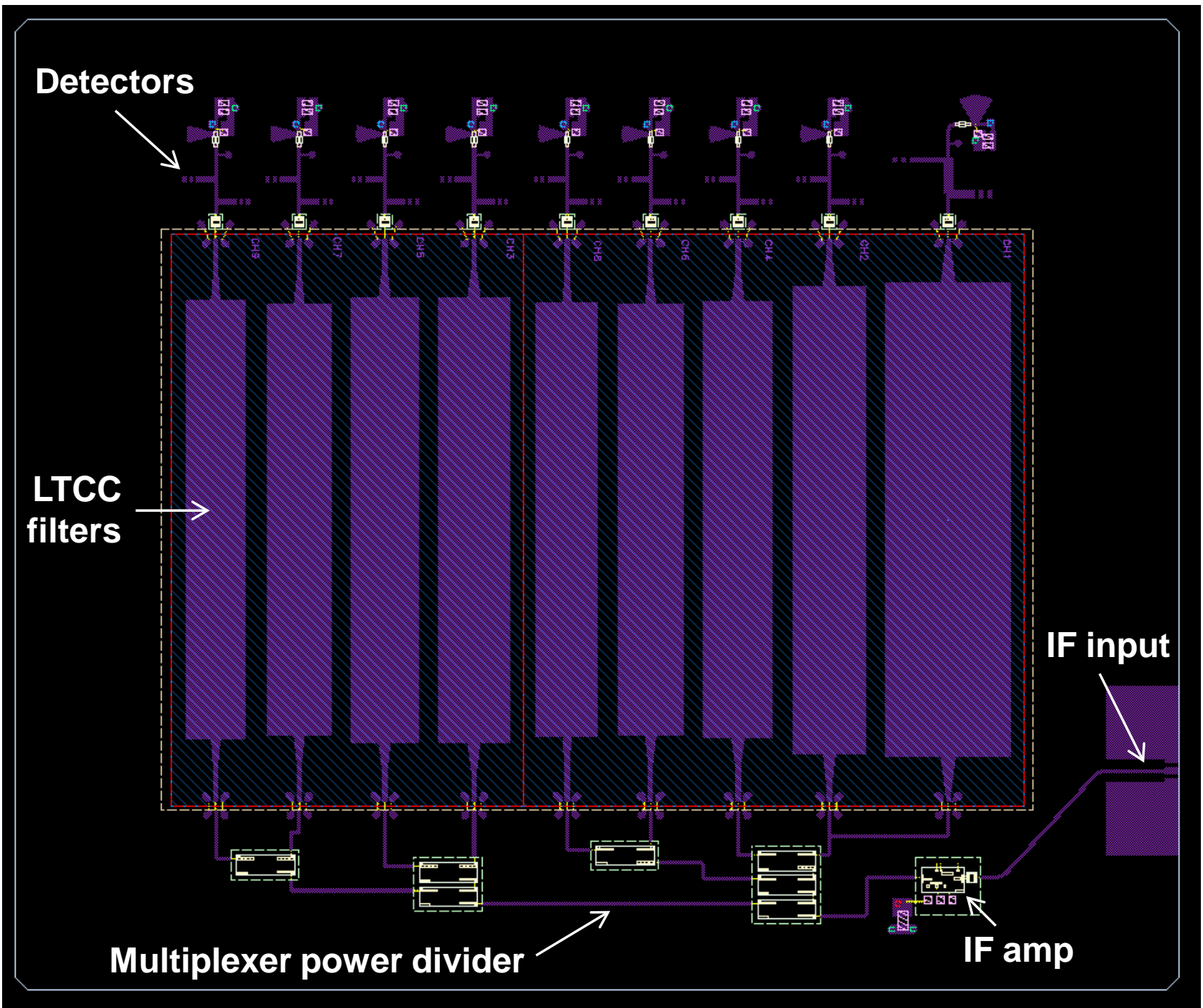




\section{9-ch IFP Prototype Block Diagram}

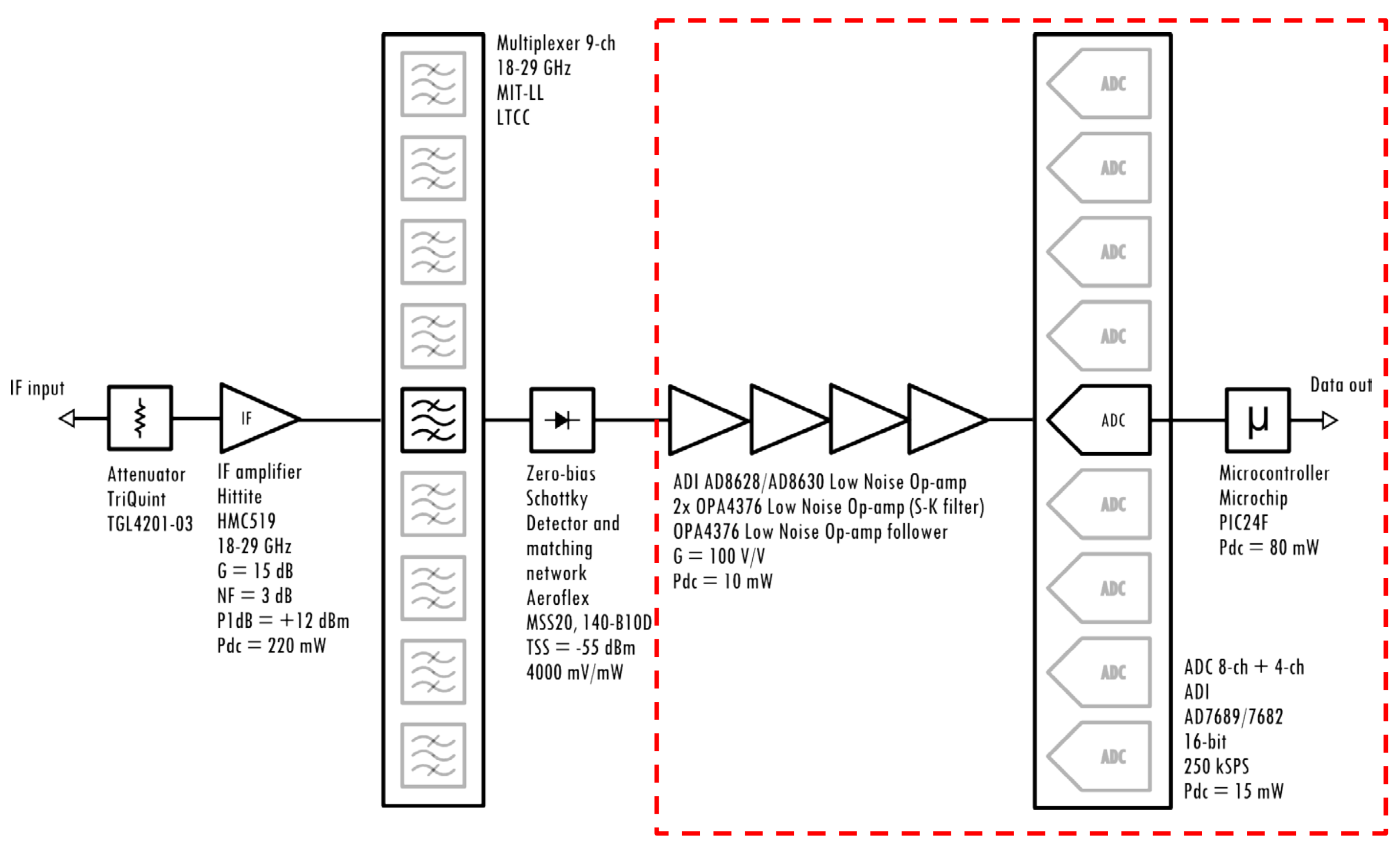




\section{IFP Board - Power Dissipation Contributors}

- Beginning thermal analysis of IFP board
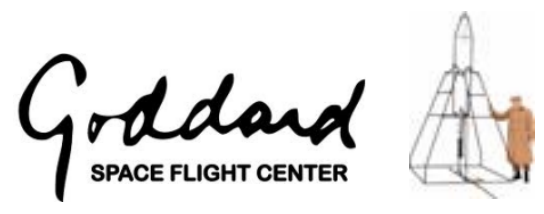

- Major power dissipation contributors identified and modeling is underway

- Foresee no difficulty with metal enclosure providing heat sink

IFP Printed Circuit Board Assembly (TOP VIEW)

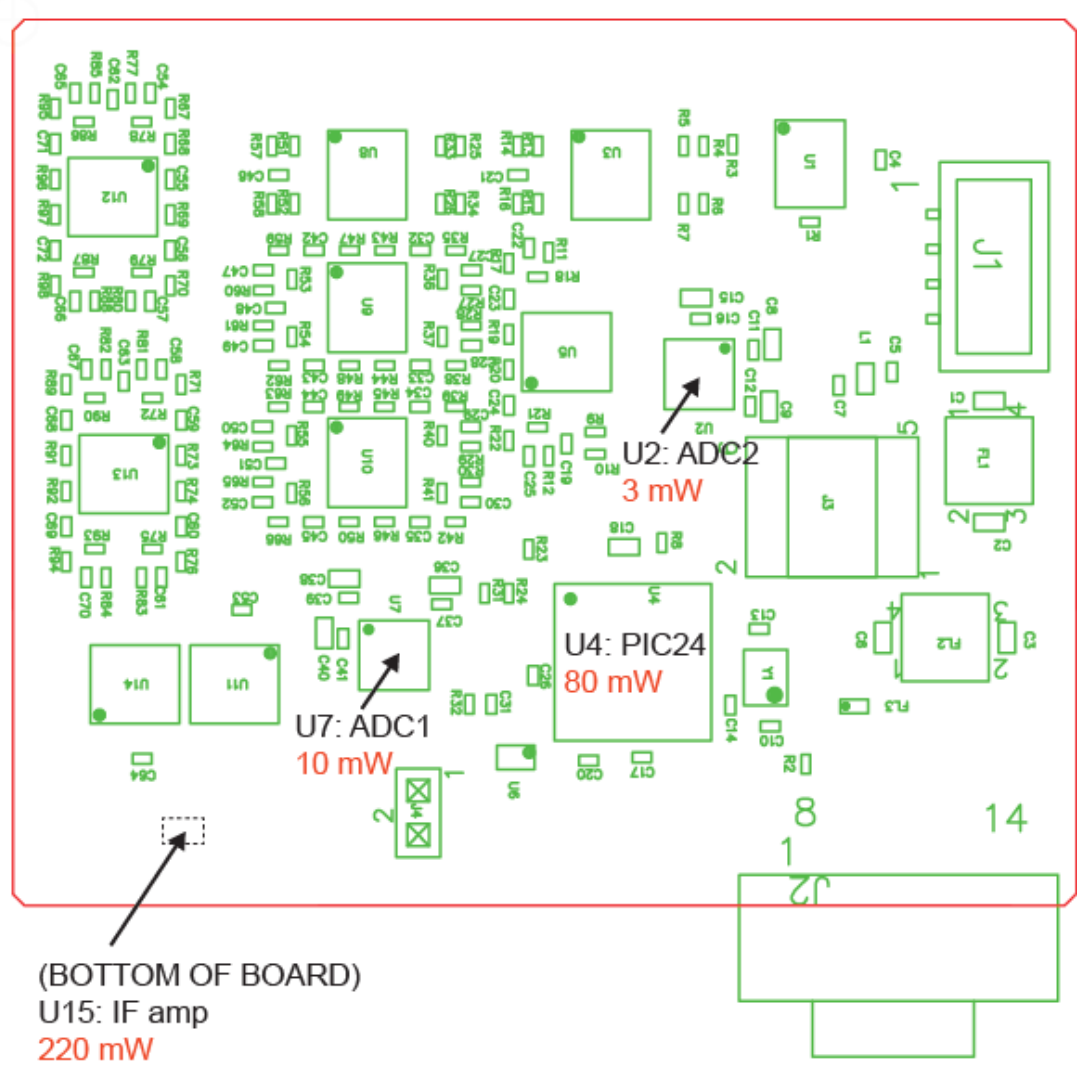




\section{Mechanical Design}

Mechanical drawings of the CoSMIR/CoSSIR scanhead have been stripped and a new model for the HyMAS has been created

Scanhead will contain

- Two $118 \mathrm{GHz}$ and One $183 \mathrm{GHz}$ antenna

- Four $118 \mathrm{GHz}$ receivers

- Two $183 \mathrm{GHz}$ receivers

- MIT-LL IF processor

-Two-card PC104 Stack

- Power conditioning and

temperature sensors

Initial layout with faux components help identify packaging challenges and constraints on component designs
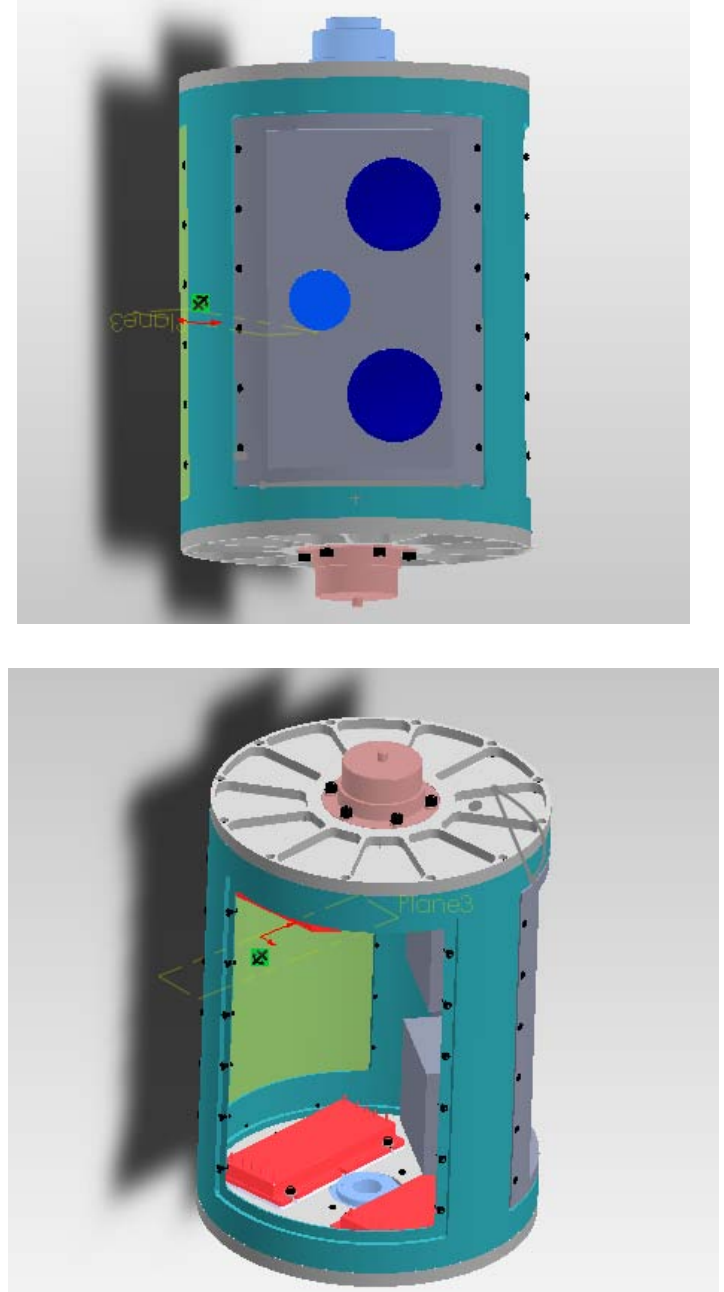


\section{Mechanical Layout}

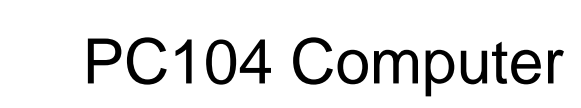

IF Processor $(10 \mathrm{~cm} \times 10 \mathrm{~cm} \times 1 \mathrm{~cm})$

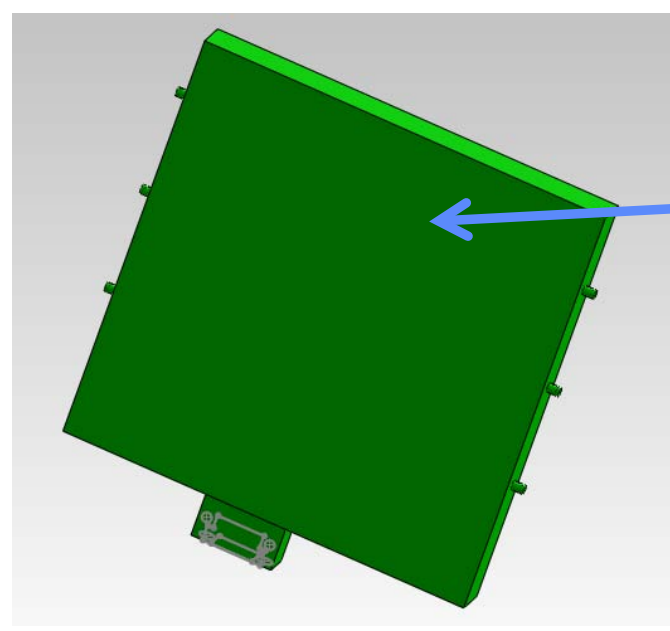

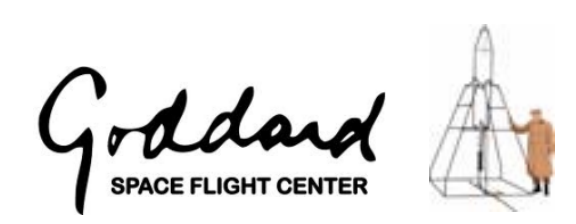

NA SAA

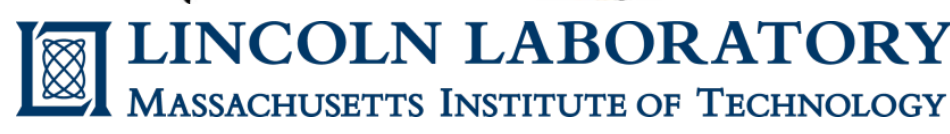

One $183 \mathrm{GHz}$ and two $118 \mathrm{GHz}$ antennas 


\section{IF Processor Requirements}

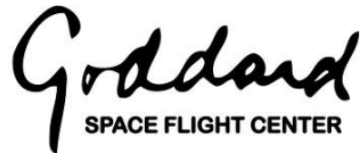

MassachusetTS INSTITUTE OF TECHNOLOGY

\begin{tabular}{|l|l|l|}
\hline \multicolumn{2}{|c|}{ Requirement } & \multicolumn{1}{c|}{ Tests } \\
\hline Size & $<1 \mathrm{~cm} \times 1 \mathrm{~cm} \times 0.1 \mathrm{~cm}$ & None \\
\hline DC Power & $<650 \mathrm{~mW}$ & Swept frequency, power \\
\hline Channel isolation & $>40 \mathrm{~dB}$ & Swept frequency \\
\hline Channel passband ripple & $<1.5 \mathrm{~dB}$ & Swept frequency \\
\hline Channel amplitude balance & $<1 \mathrm{~dB}$ & Swept frequency \\
\hline $\begin{array}{l}\text { Total gain, from input to } \\
\text { diode detector input }\end{array}$ & $5 \mathrm{~dB}<\mathrm{G}<10 \mathrm{~dB}$ & Swept frequency, power \\
\hline DC Power Noise & $<100 \mathrm{mV} \mathrm{p-p} \mathrm{ripple}$ & Swept frequency, power \\
\hline Temperature, operational & $-40^{\circ} \mathrm{C}<\mathrm{T}<+85^{\circ} \mathrm{C}$ & Swept frequency \\
\hline Data interface & $\mathrm{SPI}$ bus & System test \\
\hline
\end{tabular}




\section{SIW Filter Measurements - S21 wideband}
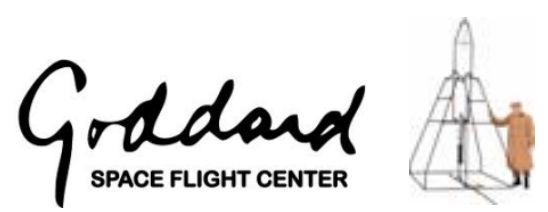
(105)

LINCOLN LABORATORY

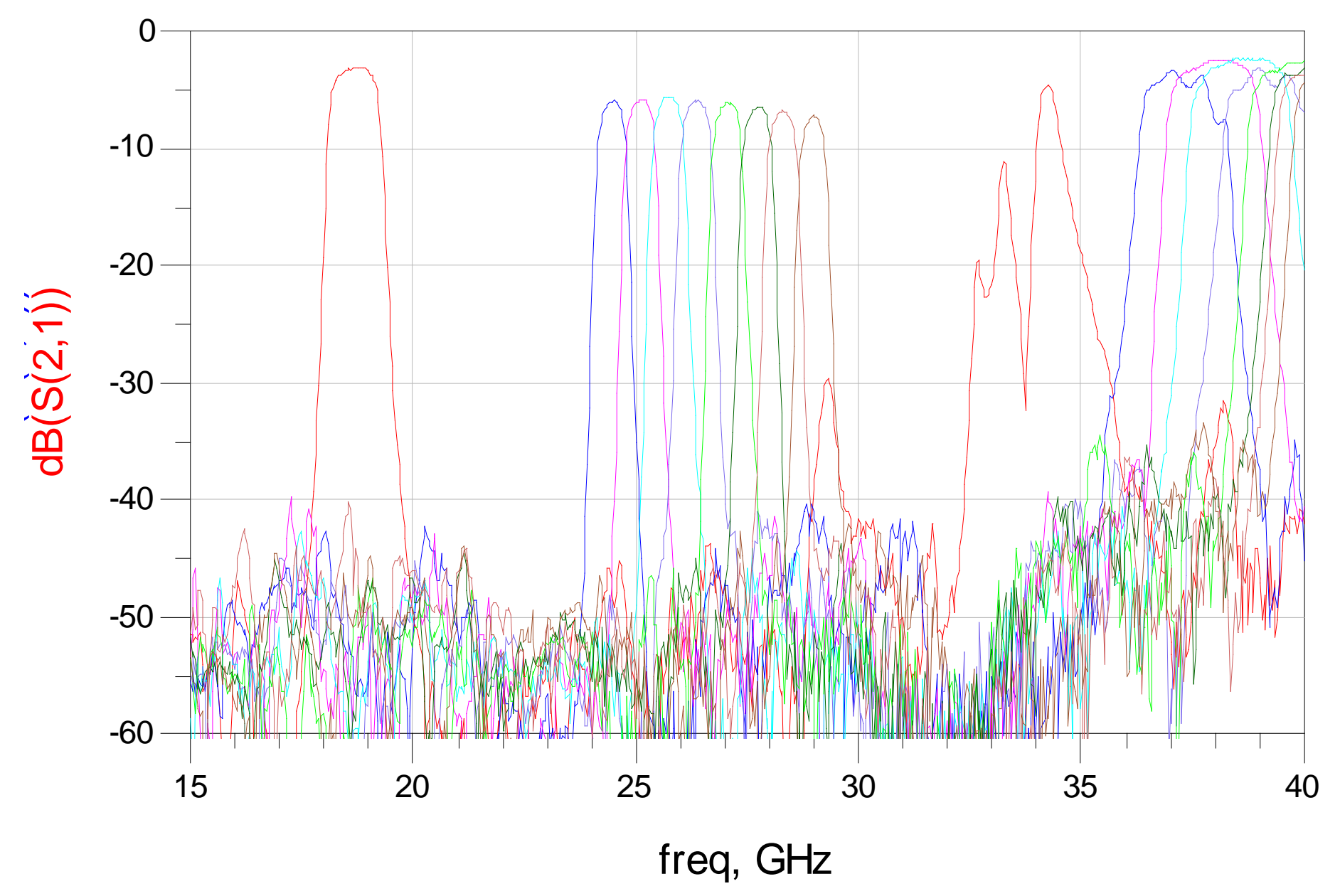




\section{Outline}

- Overview

- HyMAS frontend architecture/frequency plan/design

- Prototype IF processor Design and Mechanical Accommodation

- Interoperable Remote Component (IRC) and the Scanhead Computer

- Summary and Next Steps 


\section{The PIC24 processor puts 52 channels in a serial stream}

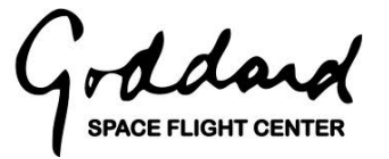

圆

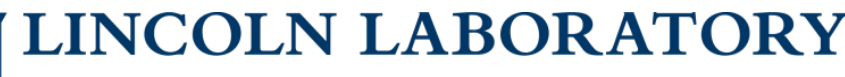

MassachuSETTS INSTITUTE OF TeChNOLOGY

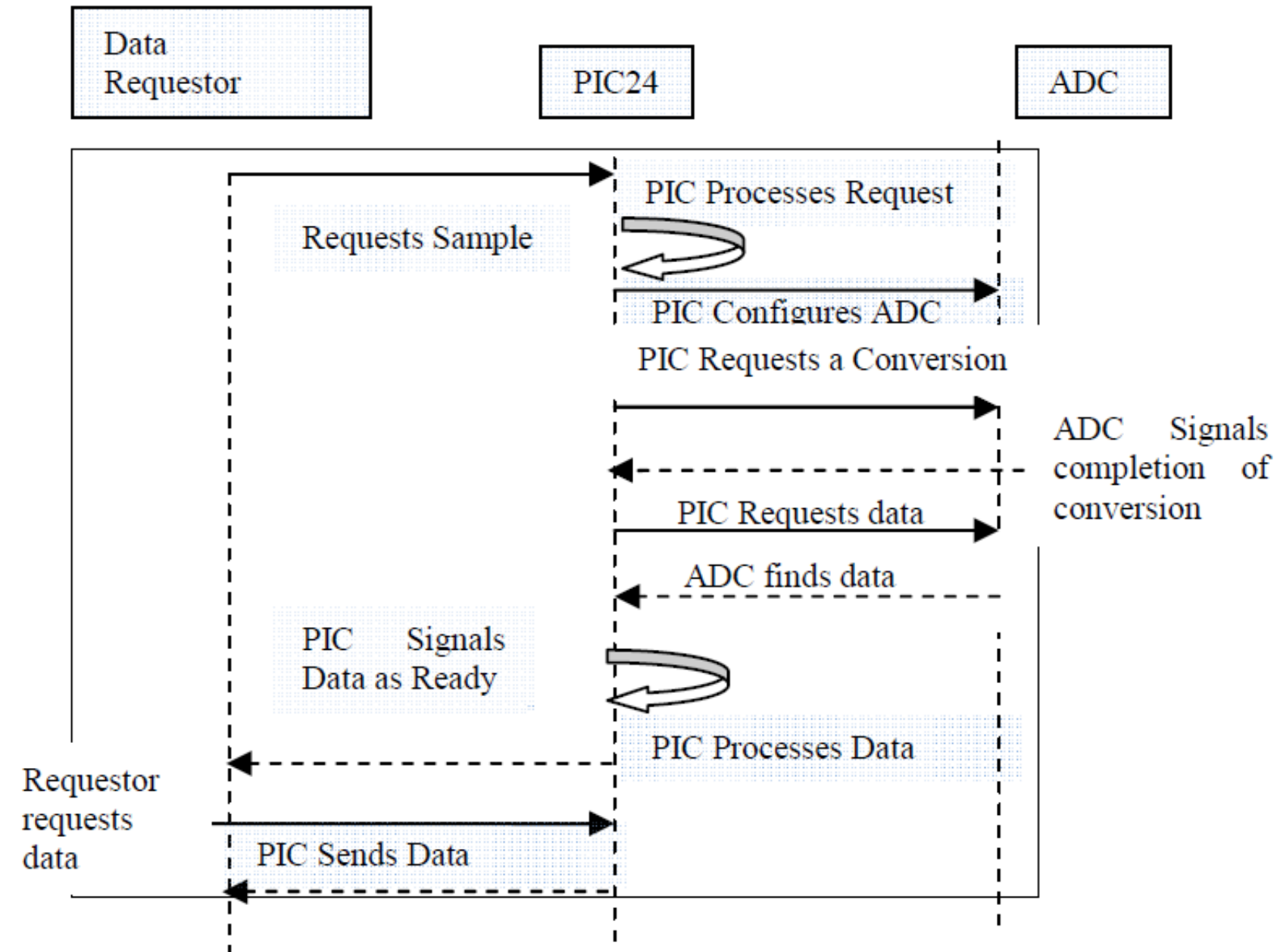

Figure 5c: 'Hand-shaking between back end components 
Interoperable Remote Component (IRC) will update CoSMIR/CoSSIR and accommodate HyMAS

Radar/Radiometer Data System Testbed

(for COSMIR, WISM, HYMAS, DBSAR, ECOSAR, etc)

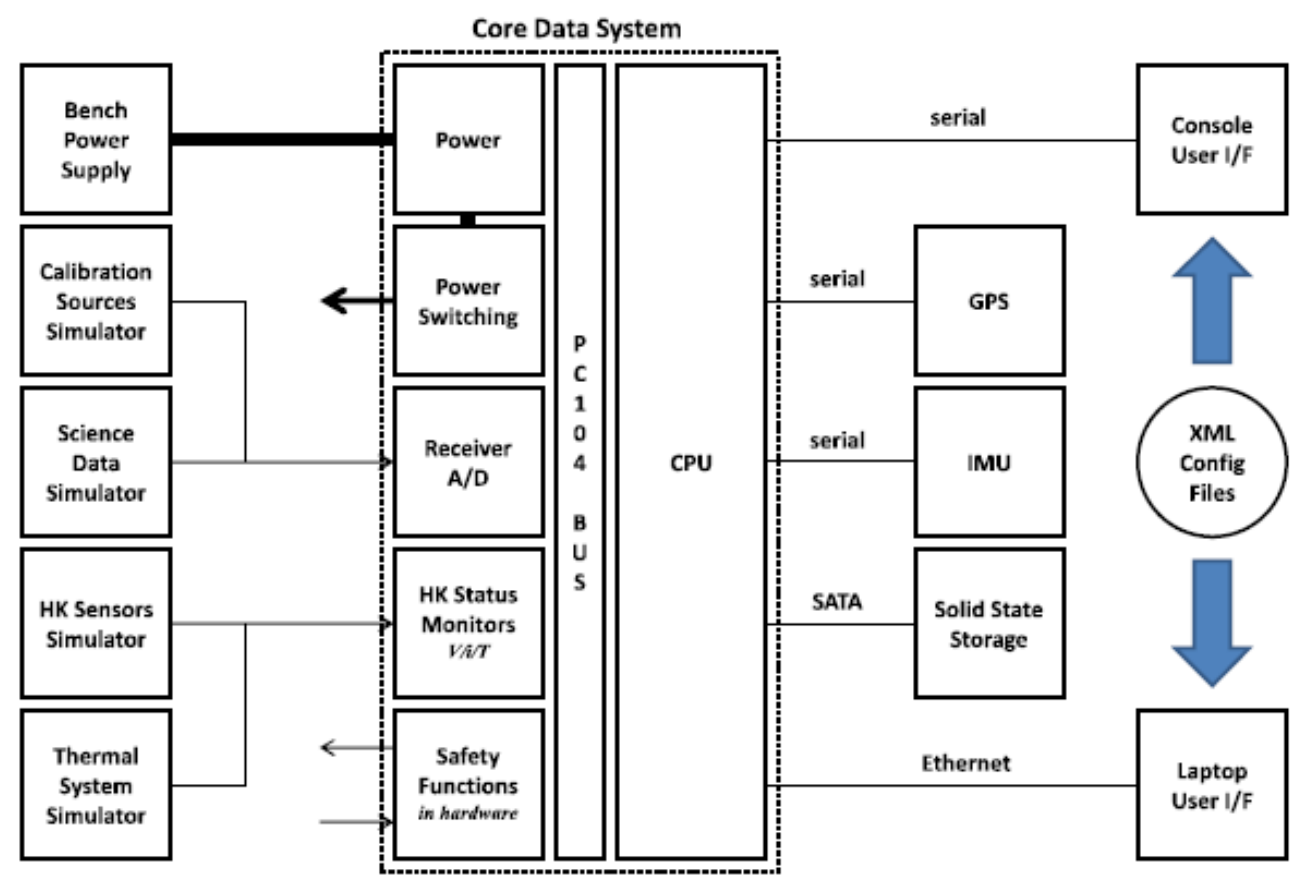

$8 / 31 / 2012$
The additional channels required for HyMAS are not a problem for IRC and the degree of automated operation required for CoSMIR/CoSSIR are lessons learned that the IRC can re-apply for HyMAS.

Figure 7: The general IRC test bed being developed for multiple aircraft instruments-block diagram by Beth Timmons Goddard Science Data Processing Branch 


\section{Hyperspectral IFP and Scanhead Computer Serial Peripheral Interface (SPI)}
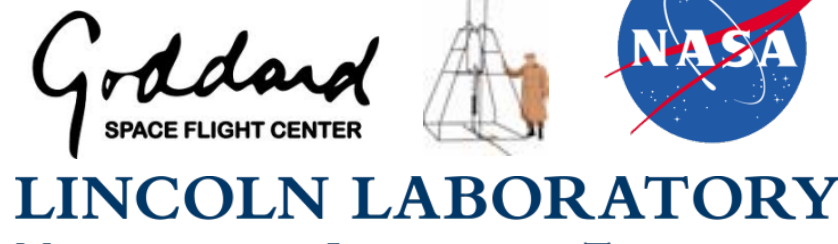

MASSACHUSETTS INSTITUTE OF TECHNOLOGY

\section{Test Bed Diagram}

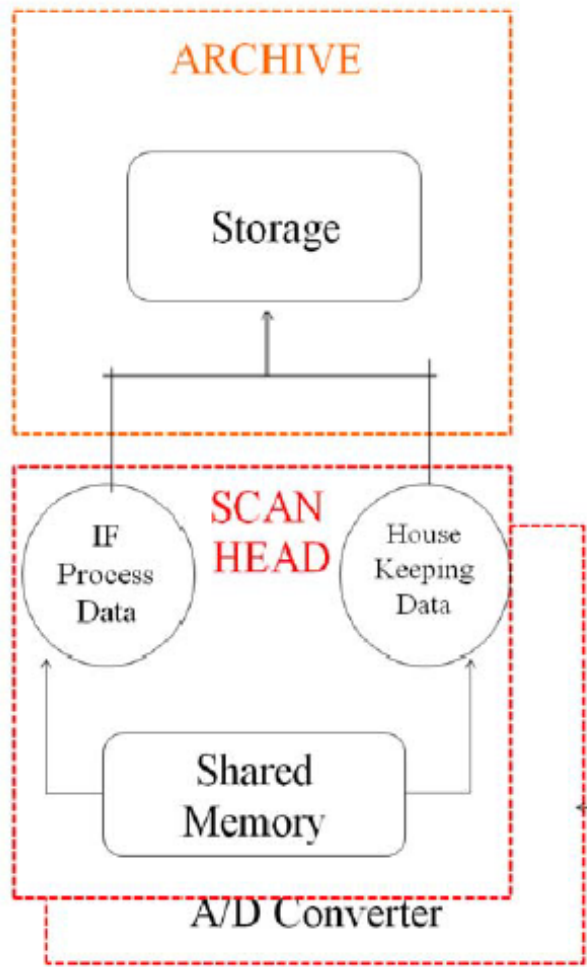

Pinout:

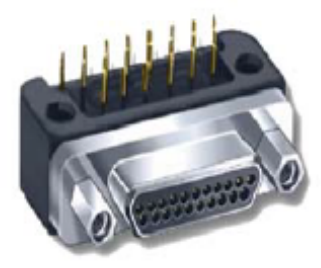

1. Start Channel Scan 6. SPI: SS

2. Data Ready 7. $+5 \mathrm{~V}$

3. SPI: SCLK 8. Spare Conn.

4. SPI: MOSI 9. GND

5. SPI: MISO

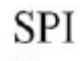

Bus

\section{MICROCONTROLLER}

Data

Figure 5b: The Scan head computer will pull the data from the IFP over a serial peripheral interface (SPI) [6]

The HyMAS test bed must simulate the collection and system clock time-tagging of data . The calibration computer and navigation data are also time tagged and archived together for post-flight processing. 


\section{Outline}

- Overview

- HyMAS frontend architecture/frequency plan/design

- Prototype IF processor Design and Mechanical Accommodation

- Interoperable Remote Component (IRC) and the Scanhead Computer

- Summary and Next Steps 


\section{Summary and Next Steps}

- LTCC filter prototype bank 1 (of 6) fabricated and tested

- Very good S-parameter performance

- Additional tests ongoing

- "Horizontal resonator" architecture implemented

- Fabrication tolerances characterized

- Filter "carrier board" with power divider, detectors, signal conditioning, and digital processing fabricated

- Analysis of ultra-compact "vertical resonator" architecture (goal) looks very good; completion of design and fabrication run planned for early 2013.

- Digital firmware for carrier board complete

- Finish Integration in time for Flight Opportunity in Summer of 2014 


\section{Gradand}

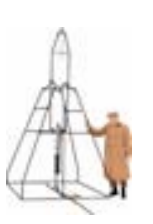

\section{Thank you}

\section{Questions}




\section{Gradand}

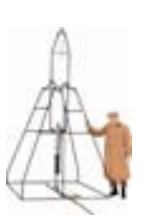

\section{Back up}

\section{Charts}




\section{PI: William Blackwell, MIT Lincoln Laboratory}

\section{Objective}

- Develop and demonstrate a new hyperspectral microwave receiver subsystem to support future atmospheric sounding missions such as PATH.

- Achieve an all-weather sounding capability through broadband 118 and $183 \mathrm{GHz}$ receiver subsystems.

- Core technology effort is an ultra-compact $\left(4100 \mathrm{~cm}^{3}\right.$. $500 \mathrm{~g}$ ) Intermediate Frequency (IF) processor module enabling hyperspectral sensing within the mass/volume envelope of current systems.

- Enable smaller sensors with greater reliability, launch opportunities, and performance with the proposed IF technology, together with recent RF advancements.

\section{Approach}

- Develop an integrated hyperspectral microwave receiver subsystem in a flight-ready compact package.

- Low-temperature co-fired ceramic (LTCC) process allows small feature size and multilayer integration.

- New broadband mixer technology allows many broad channels to be measured across the IF passband.

- Verify performance through ground-based radiometric and thermal testing.

\section{Co-Is/Partners:}

Paul Racette, 6SFC: Tim Hancock. MIT/LL

\section{Detection/Video Amps}

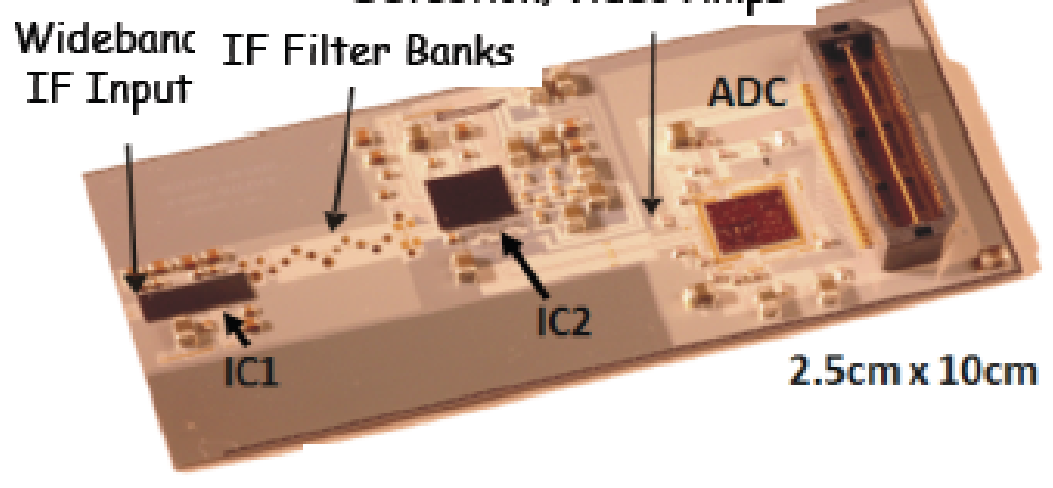

Ultra-compact LTCC filter bank and digital processor

\section{Key Milestones}

- Develop requirements and interface control document 06/12

- Design review of IF processor module

- Fabricate prototype IF filter bank

$11 / 12$

- Conduct thermal testing of prototype IF filter bank

- Assemble and test $118 \mathrm{GHz}$ front end

- Assemble and test $183 \mathrm{GHz}$ front end

- Fabricate final IF filter bank

$11 / 13$

- Complete IF processor module functional testing

- Complete mechanical integration and thermal testing

$06 / 14$

- Complete integrated subsystem environmental testing

$11 / 14$

$$
\mathrm{TRL}_{\text {in }}=3 \quad \mathrm{TRL}_{\text {current }}=\mathbf{3}
$$




\section{CoSMIR/CoSSIR Scan Head accommodating HyMAS: The work ahead}

$\leftarrow$ - Integrate the inside

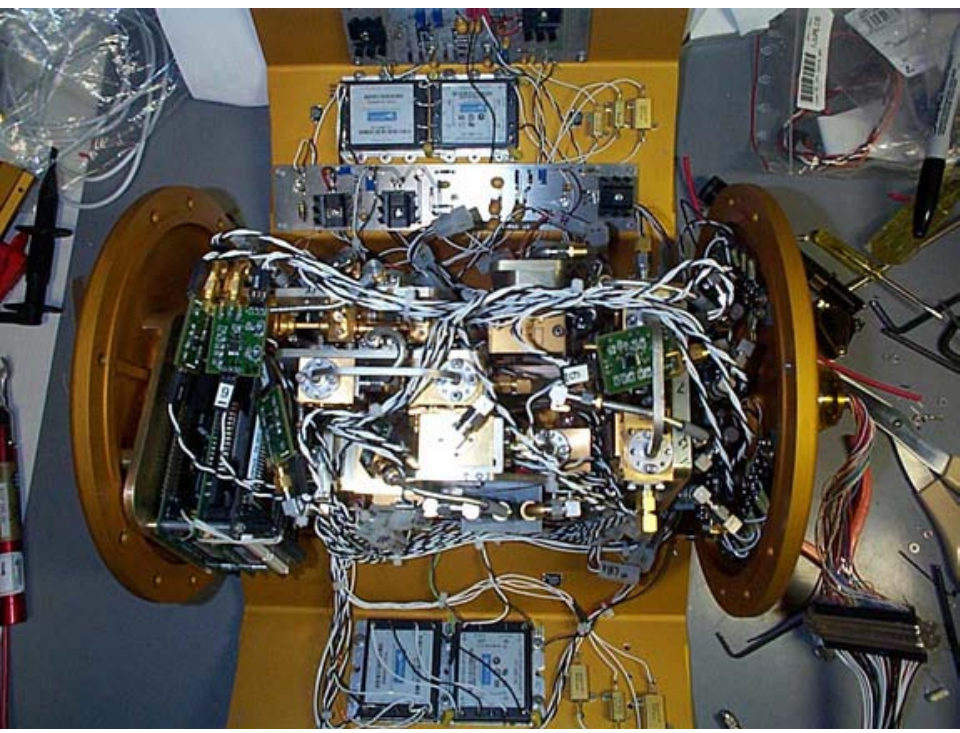

MASSACHUSETTS INSTITUTE OF TECHNOLOGY

-Successful Demonstration of high IF $18-29 \mathrm{GHz}$ in front end

-Successful demonstration of 52 Hyperspectral Channels

-Successful Data Collection and metadata collection using the IRC

Integrate the Outside - $\rightarrow$

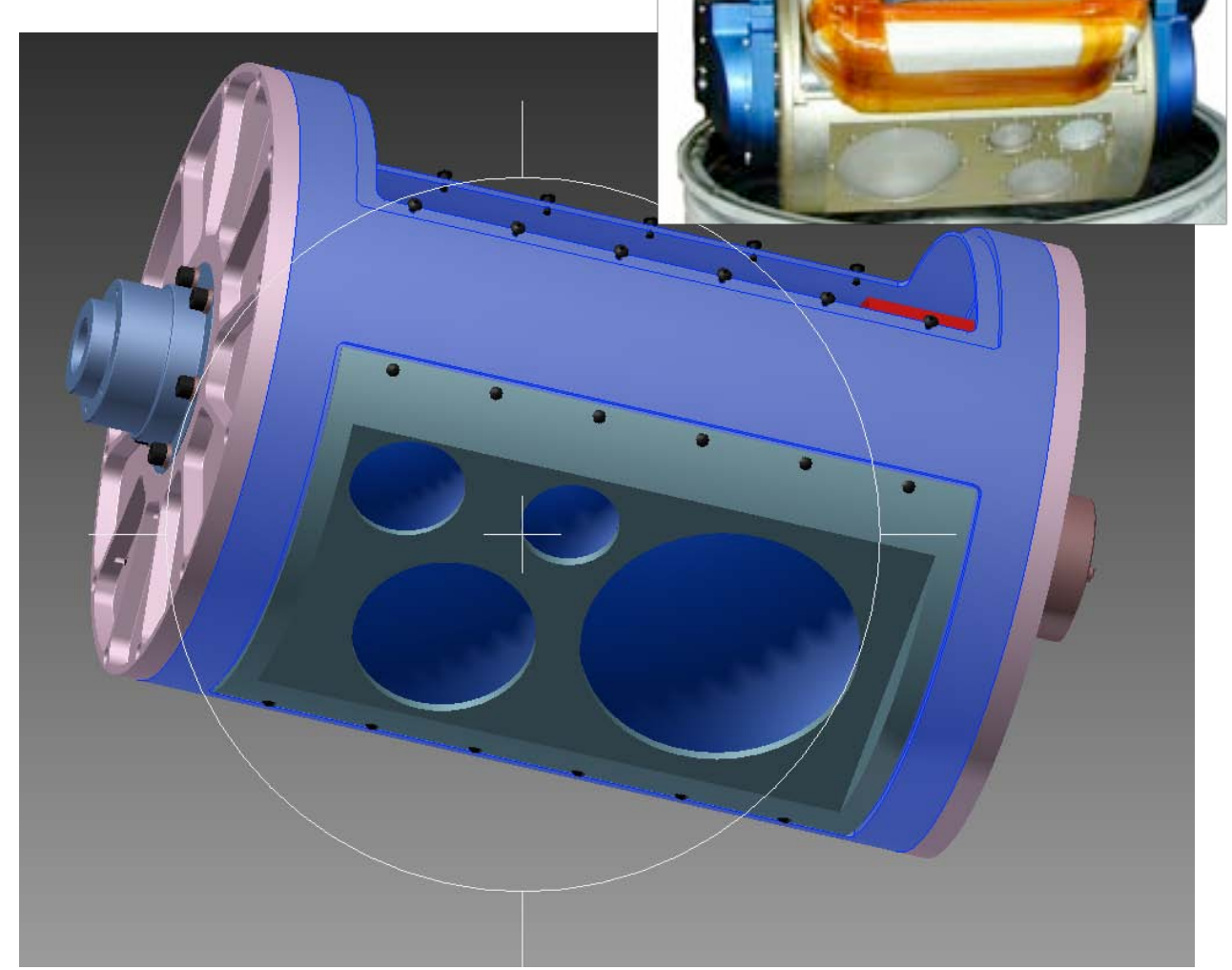




\section{CoSMIR/CoSSIR/HyMAS Scan Head}

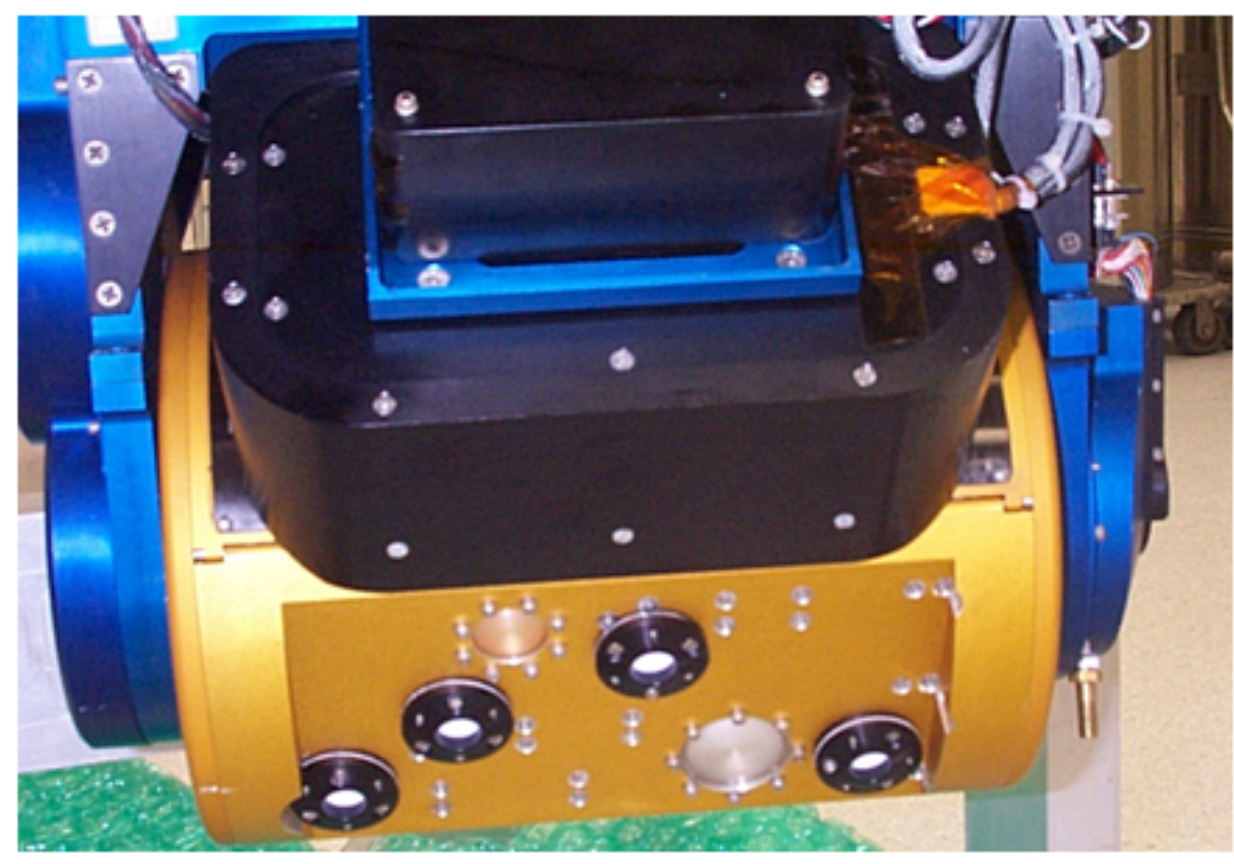

The scan head provides calibration and control infrastructure and rotates in azimuth and elevation. CoSSIR is shown in the photo at left.

A compact drum houses the radiometer electronics and rotates relative to the scan head

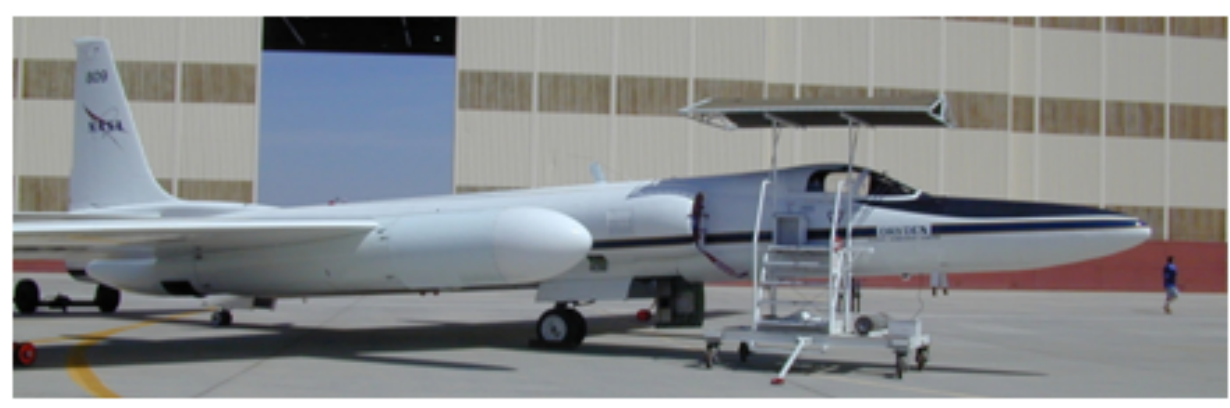

Flights on the ER-2 have produced many hours of highquality radiometric data 